\section{Mantelzelllymphom: Sensibler Test für Biomarker}

\author{
Hämatologen und Immunhämatologen aus Dänemark entwickelten \\ einen quantitativen PCR-Test, mit dem der Biomarker SOX11 bestimmt \\ und für das Monitoring des Mantelzelllymphoms genutzt werden kann.
}

OX11 ist ein Transkriptionsfaktor, $S$ der im Zellzyklus und in der Zelldifferenzierung eine wichtige Rolle spielt. Im Gegensatz zu anderen NonHodgkin-Lymphomen scheint speziell beim Mantelzelllymphom (MCL) die Expression des SOX11-Gens erhöht zu sein.

Für den Nachweis des Gens verwendeten Kristiane H. Hamborg und Kollegen eine quantitative Polymerase-Kettenreaktion mit vorgeschalteter reverser Transkriptase (RT-qPCR), mit der spezifisch die messenger-RNA für die $\mathrm{Ex}$ pression von SOX11 bestimmt und quantifiziert werden konnte.

Die Expression von SOX11 war bei 21 Patienten mit aktueller Diagnose eines Mantelzelllymphoms gegenüber 18 ge- sunden Kontrollprobanden hochsignifikant gesteigert. Dies galt sowohl für die Bestimmung aus EDTA-Blut wie auch aus dem Knochenmark.

Die SOX11-Bestimmung zeigte nur bei zwei Kontrollprobanden eine (sehr niedrige) Expression. Dagegen wies ein kommerziell erhältlicher quantitativer Genexpressions-Assay für das bei MCL typischerweise überexprimierte ZyklinD1-Gen (CCND1) bei allen Blutproben und mit einer Ausnahme bei allen Knochenmarkspunktaten der Kontrollgruppe eine (niedrige) CCND1-Expression nach.

Um die Sensitivität des SOX11-Tests mit der des CCND1-Assays zu vergleichen, verwendeten die Forscher Mantelzelllymphom-Zellen aus der Zelllinie
Granta-519. Diesen Zellen fügten sie so lange mononukleäre Zellen gesunder Probanden hinzu, bis die Assays die Expression von SOX11 bzw. CCND1 nicht mehr anzeigten. Dabei war für die SOX11-Bestimmung die Sensitivität mit $2 \times 10^{-4}$ größer als beim CCND1-Assay mit $2 \times 10^{-3}$.

In einer Langzeitbeobachtung korrespondierten die SOX11-Werte von Patienten auch mit deren klinischem Verlauf, etwa mit Anstieg beim Rezidiv bzw. Abfall bei kompletter Remission.

Fazit: Nach den Ergebnissen dieser aktuellen Studie ist die Bestimmung des Biomarkers SOX11 mittels quantitativer PCR eine valide Methode für den Aktivitätsnachweis eines Mantelzelllymphoms. Dieses Verfahren scheint dabei der Bestimmung von Zyklin D1 überlegen.

Andreas Fischer

Hamborg KH et al. A highly sensitive and specific qPCR assay for quantification of the biomarker SOX11 in mantle cell lymphoma. Eur J Haematol. 2012;89(5):385-94.

\title{
Zellen des Mantelzelllymphoms werden durch Interleukin 6 geschützt
}

Für das Wachstum vieler Tumoren sind das umgebende Gewebe und von ihm ausgeschüttete Faktoren ebenso wichtig wie die Tumorzellen selbst. Amerikanische Kollegen haben den Effekt von Interleukin 6 auf Mantelzelllymphome (MCL) analysiert. Demnach verstärkt dieses Zytokin das Tumorwachstum und schützt die Lymphomzellen vor Chemotherapeutika.

Z unächst bestimmten die Forscher des MD Anderson Cancer Center, Houston, TX/USA, die Produktion von Interleukin 6 (IL-6) in MCL-Zellen. Die bekannten MCL-Zelllinien SP53 und Granta-519 sowie primäre Tumorzellen von Patienten synthetisierten große Mengen von IL-6. Für die MCL-Zelllinien Mino und Jeko-1 war keine Produktion des Zytokins nachweisbar.

Den löslichen Anteil des IL-6-Rezeptors gp80 sezernierten alle vier Zelllinien sowie die Lymphomzellen der Patienten. Alle MCL-Zellen exprimierten auch den Transmembran-Rezeptoranteil gp130.

In der Zellkultur führte die Gabe von neutralisierenden Antikörpern gegen IL-6 oder von gp130 blockierenden Sub- stanzen zu einer früheren Apoptose der Patienten-Lymphomzellen oder der Zelllinien SP53 bzw. Granta-519.

In einem weiteren Experiment wurden Lymphomzellen in der Kultur dem Proteasominhibitor Bortezomib ausgesetzt. Die Zugabe von IL- 6 bewirkte bei allen Zelllinien eine Verringerung der Bortezomib-induzierten Apoptose-Rate, während die Zugabe von Antikörpern gegen IL-6 oder gp130 diesen Effekt wieder aufhob. Den protektiven Effekt des Zytokins konnten die Autoren auch bei anderen Substanzen wie Cytarabin oder Atiprimod zeigen.

Der Rezeptorteil gp80 spielt in diesem System ebenfalls eine wesentliche Rolle: Gentechnisch veränderte MCL-Zellen
(„Knock-out-Zellen“) ohne gp80-Expression zeigten eine höhere Spontan-Apoptose als Kontrollzellen. Die durch Bortezomib erhöhte Apoptose-Rate konnte durch exogen zugeführtes IL- 6 bei den Kontrollzellen, aber nicht bei den Knockout-Zellen verringert werden. Lymphomzellen mit einer transgenen Überproduktion von gp80 waren dagegen resistenter gegen Bortezomib als Kontrollzellen. Das Team um Liang Zhang konnte nachweisen, dass IL-6 mehrere Signaltransduktionswege wie den JAK2/STAT3- und den P13K/Akt-Pathway aktiviert.

Fazit: Die Ergebnisse der vorliegenden Studie zeigen IL-6 als wichtigen protektiven Faktor für Mantelzelllymphome. Demnach wären gegen IL-6 gerichtete Therapiestrategien vielversprechende Behandlungsoptionen. Andreas Fischer

Zhang $L$ et al. Role of the microenvironment in mantle cell lymphoma: IL- 6 is an important survival factor for the tumor cells. Blood. 2012;120(18):3783-92. 